\title{
Potential for organ donation in the United Kingdom: audit of intensive care records
}

\author{
Kerri Barber, Sue Falvey, Claire Hamilton, Dave Collett, Chris Rudge
}

\begin{abstract}
Objectives To determine the true potential for solid organ donation from deceased heartbeating donors and the reasons for non-donation from potential donors.

Design An audit of all deaths in intensive care units, 1 April 2003 to 31 March 2005. The study was hierarchic, in that information was sought on whether or not brain stem testing was carried out; if so, whether or not organ donation was considered; if so whether or not the next of kin were approached; if so, whether or not consent was given; if so, whether or not organ donation took place.

Setting 341 intensive care units in 284 hospitals in the United Kingdom.

Participants 46801 dead patients, leading to 2740 potential heartbeating solid organ donors and 1244 actual donors.

Main outcome measures Proportion of potential deceased heartbeating donors considered for organ donation, proportion of families who denied consent, and proportion of potential donors who became organ donors.

Results Over the two years of the study, $41 \%$ of the families of potential donors denied consent. The refusal rate for families of potential donors from ethnic minorities was twice that for white potential donors, but the age and sex of the potential donor did not affect the refusal rate. In $15 \%$ of families of potential donors there was no record of the next of kin being approached for permission for organ donation.

Conclusions Intensive care units are extremely good in considering possible organ donation from suitable patients. The biggest obstacle to improving the organ donation rate is the high proportion of relatives who deny consent.
\end{abstract}

\section{Introduction}

The United Kingdom has a serious shortage of organs for transplantation, as does almost every country. The number of patients waiting for a kidney transplant has increased from 3954 at the end of 1994 to 5736 in 2005 and continues to rise by around $1.5 \%$ a year. In 2005, there were 1312 kidney transplants from 715 dead donors and 538 transplants from living donors. Waiting lists for liver and cardiothoracic organ transplants are artificially low as access is restricted to approximate the anticipated number of organs available for transplantation. At the end of 2005, 360 patients were registered for a liver transplant and 394 for a cardiothoracic transplant, and in that year there were 605 liver and 286 cardiothoracic transplants. Nevertheless, $6-11 \%$ of patients accepted for these lists die before an organ becomes available and a further 2-8\% are removed from the list because their condition deteriorates and transplan- tation is no longer appropriate. The number of deceased heartbeating donors has remained relatively static since 1998, ranging from 644 to 739 donors a year, having fallen from a peak of 923 in $1989 .{ }^{12}$ The heartbeating donor rate in 2004 was 12.3 per million population, which is one of the lowest rates in western Europe. Spain has an exceptional rate of 33.0 per million population, but many other countries in Europe have rates between 13 and 22 per million population (table 1$).^{3}$

Several transplant and coordinator teams in the UK have carried out local surveys into the potential for organ donation from intensive care units, but only one systematic study has ben performed, which was carried out in 1989-90 and was restricted to England and Wales. ${ }^{45}$ This estimated that in 1200-1350 patients a year death was diagnosed after brain stem tests and that half of these patients became actual organ donors. It also reported that, when approached, $30 \%$ of relatives of potential donors refused consent for organ donation, though differences in methods prevent direct comparisons with our study.

UK Transplant, now a division of NHS Blood and Transplant, was established in 2000 with a specific responsibility to introduce measures to increase organ donation. As part of this process a national potential donor audit was developed to identify the true potential for organ donation from dead donors, together with the reasons for non-donation. ${ }^{6}$ These data will identify where in the process, and for what reason, potential donors fail to become actual donors. This allows focused initiatives to be introduced to address shortcomings of the system in a specific way. We describe the establishment and implementation of the potential donor audit together with the overall results from the first two years for potential heartbeating donors.

\section{Methods}

The potential donor audit was designed on a hierarchical basis. Basic demographic information (not patient identifiable) is obtained for all patients who die in an intensive care unit, together with date, time, and cause of death. This is followed by questions concerning whether or not death was diagnosed by brain stem testing, whether or not solid organ donation was considered, the process by which relatives were approached, and whether or not consent was obtained. Finally, information is requested on whether or not organs were offered for transplantation and whether or not organ donation occurred.

After an extensive pilot study, the final version of the audit form was developed (see bmj.com). Data are collected by donor

The audit form is on bmj.com 
Table 1 Rates of heartbeating donation (per million population) in some European countries, 2004

\begin{tabular}{lc} 
Country & Rate \\
\hline Austria & 22.2 \\
\hline Belgium & 21.3 \\
\hline Denmark & 11.9 \\
\hline Finland & 20.9 \\
\hline France & 21.0 \\
\hline Germany & 13.1 \\
\hline Greece & 6.0 \\
\hline Ireland & 16.7 \\
\hline Italy & 21.1 \\
\hline Netherlands & 8.3 \\
\hline Portugal & 22.2 \\
\hline Spain & 33.0 \\
\hline Sweden & 13.7
\end{tabular}

transplant coordinators, donor liaison nurses, and some intensive care unit link nurses. All forms are submitted to UK Transplant for data entry and validation checks, with any queries being resolved whenever possible with the person who completed the form. Strenuous efforts are made to ensure that the study includes all intensive care units in the UK with the potential for providing deceased heartbeating solid organ donors and that forms for all deaths are completed. This includes regular comparisons between the actual numbers of deaths and the number of forms received.

Fully validated data on deaths in intensive care units are available from 1 April 2003. In the first two years of the audit, up to March 2005, data were obtained on 46801 deaths in 341 intensive care units in 284 different hospitals.

\section{Results}

The figure shows a schematic breakdown of the 46801 audited deaths. In summary, $91 \%$ of the patients were being mechanically ventilated at some point during their stay in the intensive care unit. Of those, $2740(6 \%)$ were potential heartbeating donors in that death was diagnosed by brain stem testing and there were no absolute medical contraindications to heartbeating solid organ donation. For $420(15 \%)$ of the families of the 2740 potential donors there was no record of discussion or approach regarding organ donation with the next of kin. Reasons given for the lack of discussion include the patient's general medical condition or the next of kin stating that they would not give permission before being asked. Of the 2320 families who were approached or initiated an approach, $59 \%$ gave consent for heartbeating organ donation, and $1244(90 \%)$ of the 1379 patients became organ donors. Around $41 \%$ of families denied consent $(95 \%$ confidence interval $38.6 \%$ to $42.6 \%)$. We refer to this as the refusal rate.

Table 2 shows the main reasons given for relatives' lack of consent. Individuals may have given more than one reason. No single reason was given much more commonly than the others. Other reasons for refusal were given by 244 families (26\%) and included "the family wanted to be with the patient when the ventilator was turned off," "religious beliefs," and "the family do not agree with organ donation."

Table 3 shows the refusal rate by sex, age group, and ethnicity. Information on sex, age, and ethnicity was not available for all 2320 potential donors, and so the table gives the numbers in each group on which the refusal rate is based. The refusal rates for males and females and the six age groups did not differ significantly. There is strong evidence of a difference in white and

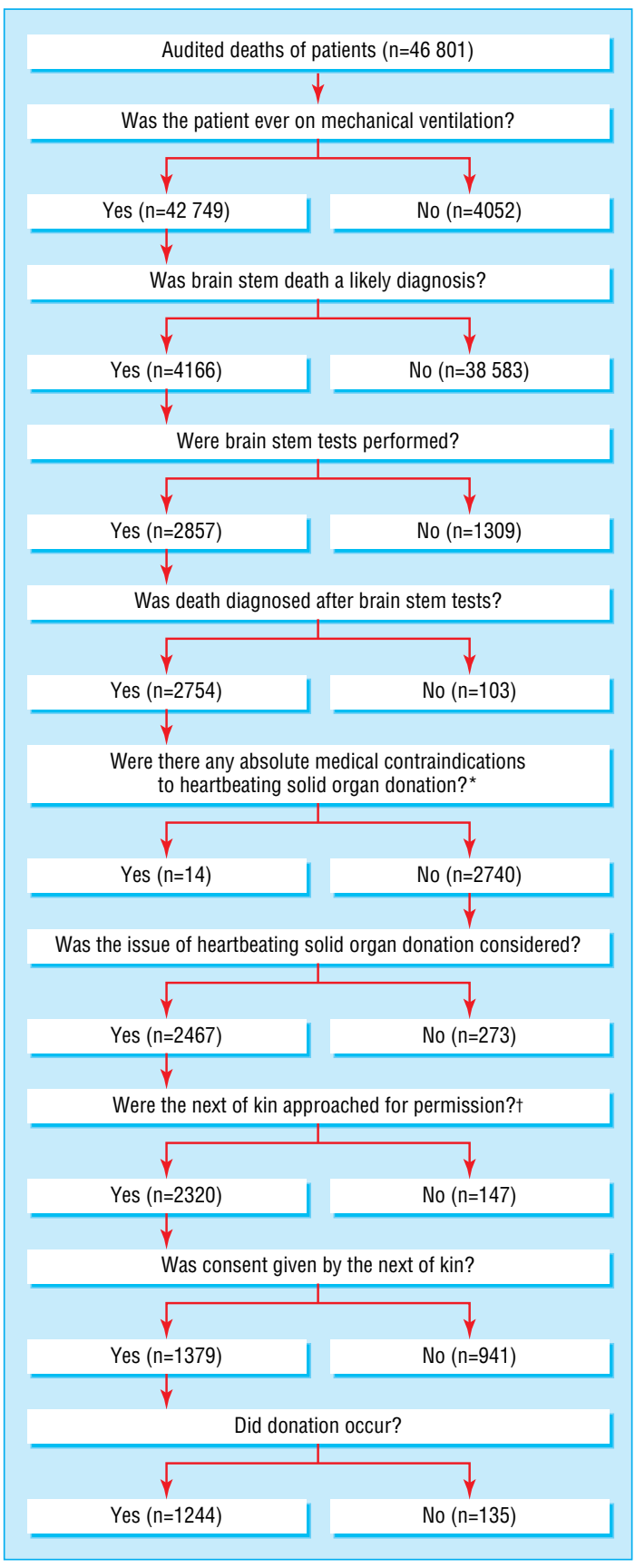

A breakdown of the 46801 audited deaths ( ${ }^{*}$ either known or suspected variant Creutzfeldt-Jakob disease or known HIV infection; tincludes cases where the next of kin made the approach)

non-white potential donors based on the 2174 potential

Table 2 Reasons given by relatives for denying consent to solid organ donation

\begin{tabular}{lc} 
Reason & Proportion $^{*}$ \\
\hline Patient stated in the past he/she did not want to be a donor & 16 \\
\hline Relatives not sure whether patient would have agreed to donation & 19 \\
\hline Relatives divided over decision & 16 \\
\hline Relatives thought patient had suffered enough & 16 \\
\hline Relatives did not want surgery to body & 20 \\
\hline Reason not documented & 17 \\
\hline
\end{tabular}

* Of 941 who refused. 
Table 3 Rate of refusal from relatives of potential heartbeating donors according to sex, age group, and ethnicity

\begin{tabular}{lccc} 
Factor & No of patients & Refusal rate (\%) & P value \\
\cline { 1 - 3 } Sex: & & & \\
\hline Male & 1197 & 40 & \multirow{2}{*}{0.83} \\
\hline Female & 1118 & 41 & \\
\hline Age (years): & & & \multirow{2}{*}{0.85} \\
\hline $0-17$ & 186 & 42 & \\
\hline $18-24$ & 177 & 40 & \\
\hline $25-34$ & 238 & 43 & \\
\hline $35-49$ & 774 & 40 & \\
\hline $50-59$ & 564 & 41 & $<0.001$ \\
\hline$\geq 60$ & 379 & 38 & \\
\hline Ethnicity: & & & \\
\hline White & 2012 & 35 & \\
\hline Asian & 82 & 77 & \\
\hline Black & 48 & 51 & \\
\hline Other & 32 & 50 & \\
\hline
\end{tabular}

heartbeating donors whose ethnicity was recorded, the refusal rate for whites being $35 \%$ (33\% to 37\%), while that for the group of ethnic minorities is $70 \%$ (63\% to $77 \%)$. More detailed analyses using logistic regression modelling confirmed these results.

\section{Discussion}

The national potential donor audit is the first comprehensive, UK-wide study to try to identify the number of patients dying in intensive care units who could donate their organs for transplantation. It does so by recording information on every patient who dies in intensive care in the UK, which gives a more accurate picture than can be obtained from extrapolations derived from local studies. While it would be ideal to collect all data contemporaneously, the practicalities of the process mean that data have been collected within two to four weeks of each death. This does not seem to have resulted in missing data, which is a tribute to the assiduity of the donor coordinators and their colleagues who have collected the data. It is also important to note that data collection has taken place with the agreement and full cooperation of intensive care units but has not relied solely on the staff for data collection.

\section{Potential for organ donation}

The starting point for heartbeating organ donation is the number of patients whose death is confirmed by brain stem testing and in whom there are no absolute contraindications to organ donation (HIV or known or suspected variant CreutzfeldtJakob disease). In the two year period analysed there were 2740 such patients, which represents the maximum number of potential organ donors. This equates to a maximum achievable rate of potential heartbeating donors of 23.2 per million population per year. This maximum potential rate is well below the actual donor rate achieved in Spain. The potential donor audit shows that while in 4166 patients the diagnosis of death by brain stem testing was possible (that is, the patients were comatose, required artificial ventilation, and had unresponsive dilated pupils) only 2857 patients underwent formal testing. The outcome of the 1309 remaining patients is not known, but a proportion of these patients could have become potential heartbeating donors had brain stem death testing been performed. They may have been suitable non-heartbeating donors, and the potential donor audit has recently been extended to provide data on such patients.

\section{Approach and refusal rate}

After the diagnosis of death by brain stem testing, in 273 patients there was no record that organ donation was considered and in
147 no record that relatives were approached for consent. This amounts to $15 \%$ of potential donors, but it must be emphasised that lack of documentation of these stages does not necessarily equate to lack of consideration or approach-further data are needed to clarify this.

Of the relatives of 2320 potential heartbeating donors who were approached for consent for donation, $41 \%$ refused consent during the two years of this study. Refusal includes those situations where the relatives stated that they knew that the dead person had, in life, expressed an objection to organ donation, which comprised $16 \%$ of all refusals. When the Human Tissue Act 2004 comes into force in September 2006, the legal position will be that the wishes and consent of the individual will be paramount. It is therefore important that individuals ensure that their families are aware of their wishes in regard to organ donation. If a patient carries a signed donor card or has registered their wishes on the organ donor register, there is no legal requirement to establish lack of objection on the part of the relatives. In practice, however, if a relative denies consent, organ donation might not proceed.

\section{Conversion rate}

Differences in rates of organ donation in different areas of the $\mathrm{UK}^{7}$ and between countries ${ }^{3}$ are often expressed as differences in the donor rate per million population. This is not an appropriate measure as several factors may influence the number of potential heartbeating donors that are available. These include the provision of intensive care beds, neurosurgical practice, and the death rates from intracerebral bleeding and road traffic accidents. ${ }^{8}{ }^{9} \mathrm{It}$ is far more realistic to consider the donor rate in terms of a "percentage of the potential" or the "conversion rate." ${ }^{10}{ }^{11}$ Sheehy et al estimated the number of potential organ donors in the United States from a retrospective review of records in a sample of the organ procurement organisations. ${ }^{10}$ They found that the refusal rate for consent for organ donation was $46 \%$ and that the conversion rate (the number of actual donors divided by the number of potential donors) was $42 \%$ - a figure similar to ours (45\%). A conversion rate of $100 \%$ cannot be surpassed and therefore represents total success, whether that translates into five donors per million population or 50 donors per million population.

The UK potential donor audit seems to be the only national, ongoing study of its type in the world, and so the information that it provides is fundamental to the development of policies to improve the rate of organ donation. In this report we have focused on the methods of the study and the headline results. More detailed analyses of the data are currently being done. It is clear, however, that there are many patients who are not subject to brain stem death testing on whom further information is required; that intensive care units are extremely good, but not perfect, in considering possible organ donation from suitable patients; and that the single biggest obstacle to improved rates of organ donation from heartbeating donors is the number of relatives who refuse consent. The new legislation that comes into force in September 2006 may, in time, address this aspect and emphasises the benefits that can follow increased registrations on the NHS organ donor register.

We are grateful to all those who have contributed to this study, particularly the donor transplant coordinators and their regional managers, the intensive care societies, and critical care networks.

Contributors: KB, CH, SF, and Julie Hussey designed the audit form, implemented the study, and managed the data collection. DC, $\mathrm{CH}, \mathrm{KB}$, and Joanne Blackwell carried out the statistical analysis. DC and CR wrote the paper. CR is the guarantor.

Funding: Department of Health. 


\section{Research}

Competing interests: None declared.

Ethical approval: Not required.

1 UK Transplant. www.uktransplant.org.uk (accessed 1 Feb 2006)

2 UK Transplant. Transplant Activity Report for 2004-2005. www.uktransplant.org.uk/ukt statistics/transplant_activity_report/transplant_activity_report.jsp (accessed $1 \mathrm{Feb}$ 2006).

\section{What is already known on this topic}

In the early 1990s, the refusal rate for organ transplantation in England and Wales was 30\%

\section{What this study adds}

From April 2003 to March 2005, 41\% of relatives of potential donors in the UK declined to give consent for heartbeating solid organ donation

Families of $94 \%$ of patients who could have been solid organ donors were approached, or initiated an approach, for consent to donation

The maximum achievable potential donor rate during this study period was 23.2 per million population per year, well below the actual donor rate achieved in Spain
3 International figures on organ donation and transplantation. Council of Europe ransplant Newsletter 2005;10(1):1-44. www.coe.int/t/E/Social_Cohesion/Health/ NEWSLETTER\%20TRANSPLANT\%202005.pdf (accessed 1 Feb 2006).

4 Gore SM, Hinds CJ, Rutherford AJ. Organ donation from intensive care units in England. BMJ 1989;299:1193-7.

5 Gore SM, Cable DJ, Holland AJ. Organ donation from intensive care units in England and Wales: two year confidential audit of deaths in intensive care. BMJ 1992;304:34955.

6 Barber KM, Hussey JC, Bond ZC, Falvey SJ, Collett D, Rudge CJ. The UK national potential donor audit. Transplant Proc 2005;37:568-70.

7 Wight J Jakubovic M, Walters S, Maheswaran R, White P, Lennon V Variation in cadavwic J J J k Matesanz R, Rudge CJ. The acute shortage of donors: a UK and European perspective In: Forsythe JLR, ed. Transplantation-a companion to specialist surgical practice. 3rd ed.

9 Briggs JD, Crombie A, Fabre J, Major E, Thorogood J, Veitch PS. Organ donation in the UK: a survey by a British Transplantation Society working party. Nephrol Dial Transplant 1997;12:2251-7.

10 Sheehy E, Conrad SL, Brigham LE, Luskin R, Weber P, Eakin M, et al. Estimating the number of potential organ donors in the United States. N Engl J Med 2003;349:667-74.

11 Langone AJ, Helderman JH. Disparity between solid-organ supply and demand. NEngl JMed 2003;349:704-6.

(Accepted 21 February 2006)

doi 10.1136/bmj.38804.658183.55

UK Transplant, NHS Blood and Transplant, Bristol BS34 8RR

Kerri Barber principal statistician

Sue Falvey director of donor care and coordination

Claire Hamilton senior statistician

Dave Collett director of statistics and audit

Chris Rudge managing and transplant director

Correspondence to: C Rudge chris.rudge@uktransplant.nhs.uk 